\title{
BMJ Open Did case-based payment influence surgical readmission rates in France? A retrospective study
}

\author{
Albert Vuagnat, ${ }^{1,2}$ Engin Yilmaz, ${ }^{2,3}$ Adrien Roussot, ${ }^{1}$ Victor Rodwin, ${ }^{4}$ \\ Maryse Gadreau, ${ }^{5}$ Alain Bernard, ${ }^{6}$ Catherine Creuzot-Garcher, ${ }^{7,8}$ \\ Catherine Quantin ${ }^{1,9,10}$
}

To cite: Vuagnat $A$, Yilmaz $E$, Roussot A, et al. Did case-based payment influence surgical readmission rates in France? A retrospective study. BMJ Open 2018;8:e018164. doi:10.1136/ bmjopen-2017-018164

- Prepublication history for this paper is available online. To view these files, please visit the journal online (http://dx.doi. org/10.1136/bmjopen-2017018164).

Received 16 June 2017 Revised 30 October 2017 Accepted 19 December 2017

Check for updates

For numbered affiliations see end of article.

Correspondence to Dr Catherine Quantin; catherine.quantin@chu-dijon.fr

\section{ABSTRACT}

Objectives To determine whether implementation of a case-based payment system changed all-cause readmission rates in the 30 days following discharge after surgery, we analysed all surgical procedures performed in all hospitals in France before (2002-2004), during (20052008) and after (2009-2012) its implementation.

Setting Our study is based on claims data for all surgical procedures performed in all acute care hospitals with $>300$ surgical admissions per year (740 hospitals) in France over 11 years (2002-2012; $n=51.6$ million admissions).

Interventions We analysed all-cause 30-day readmission rates after surgery using a logistic regression model and an interrupted time series analysis.

Results The overall 30-day all-cause readmission rate following discharge after surgery increased from $8.8 \%$ to $10.0 \%(P<0.001)$ for the public sector and from $5.9 \%$ to $8.6 \%(\mathrm{P}<0.001)$ for the private sector. Interrupted time series models revealed a significant linear increase in readmission rates over the study period in all types of hospitals. However, the implementation of case-based payment was only associated with a significant increase in rehospitalisation rates for private hospitals $(\mathrm{P}<0.001)$. Conclusion In France, the increase in the readmission rate appears to be relatively steady in both the private and public sector but appears not to have been affected by the introduction of a case-based payment system after accounting for changes in care practices in the public sector.

\section{INTRODUCTION}

Financing hospitals is a challenge for any healthcare system. Many countries in the Organisation for Economic Cooperation and Development have chosen payment by diagnosis-related group (DRG). In 1983, the USA was the first country to introduce a casebased payment system according to DRGs of patients insured by Medicare. ${ }^{1-3}$ Many countries around the world ${ }^{4}$ chose to adopt this model as a tool to regulate hospital expenditure. The USA applied DRG-based reimbursement to one specific patient group, those 65 years and over (Medicare) and eventually for

\section{Strengths and limitations of this study}

To our knowledge, this is the first study to analyse 30-day all-cause readmission rates before, during and after the introduction of the case-based payment system in France.

- We linked individual patient data over 11 years for all surgical procedures performed in all acute care hospitals with $>300$ surgical admissions per year in France $(n=51.6$ million surgical admissions and 740 hospitals).

We analysed rates of readmission for surgery with logistic regression models and with an interrupted time series analysis, in order to measure changes in readmission rates over time.

- One limitation of this study is that we considered allcause readmissions as it is not possible to rule out planned readmissions in French claims data.

the poor (Medicaid). In other countries, only a part of hospital reimbursement is based on the DRG system, as in Portugal, ${ }^{56}$ where this payment system concerns only certain care activities. To our knowledge, only France and Norway have implemented this case-based payment system to finance all hospital care activities since the early 2000s. ${ }^{78}$

Other countries, like Belgium, are considering the implementation of a similar casebased payment system, ${ }^{9}$ but wonder whether it would induce certain unintended effects such as encouraging hospitals to increase their activity to improve their financial balance sheets. Moreover, whether or not there was improvement in quality of care $^{10-12}$ with regard to the decreased length of stays and in terms of mortality and readmission rates is a matter of debate. ${ }^{13-15}$ Although hospital readmissions, when considered alone, can be used as an indirect marker of healthcare quality, their value in this setting is controversial. ${ }^{16}{ }^{17}$ In addition, there is some evidence that the implementation of a tariff system based on activity would lead to an increase in 
rehospitalisation so as to maximise hospital revenues. ${ }^{18-21}$ This effect was so feared in the USA and England that policy-makers imposed penalties for hospitals with abnormally high rehospitalisation rates. ${ }^{22-24}$

The medical information system in France has gathered exhaustive data on hospital activity since 1997, well before the implementation of case-based reimbursement in 2005. It is thus possible to obtain baseline rehospitalisation rates before the implementation of the case-based payment system. Since case-based payment was applied to all hospital activities, it is relatively easy to measure the evolution of readmissions after surgical procedures over the period of implementation.

The aim of this study is to determine whether implementation of case-based payment system was associated with a change in all-cause rehospitalisation rates in France. To do this, we compared rehospitalisations before the implementation of the case-based payment system (20022004), which was introduced stepwise in the middle of the study period (2005-2008) and after the implementation (2009-2012), after adjustment for the principal characteristics of patients. Previous studies conducted in France have not analysed the evolution of readmission rates over time $^{25}$ or only examined certain regions, ${ }^{13}$ or were based only on specific diseases. ${ }^{26}{ }^{27}$ In this study, we include all surgical procedures and consider all readmissions, whatever the surgical subspecialty and cause of readmission.

\section{METHODS}

\section{Source of data}

The hospital discharge abstract database (Programme de Médicalisation des Systèmes d'Informations (PMSI)) contains individual, exhaustive and linkable but anonymous data on healthcare use for the whole French population and collects primary and associated diagnoses (secondary events and comorbidities) encoded using WHO International Statistical Classification of Diseases and Related Health Problems, 10th revision, and procedures performed during all hospital stays using the common classification system for medical procedures (Classification commune des actes médicaux). The very good quality of the French hospital database has previously been evaluated and has enabled us to carry out several epidemiological and health services research studies concerning hospitalised patients in France. ${ }^{252628-31}$ The study was approved by the National Committee for Data Protection.

\section{Population}

This study was a retrospective multicentre study based on nationwide PMSI data.

We include all patients admitted to all acute care hospitals with surgical wards (740 hospitals including 295 public hospitals and 445 private hospitals) for surgical procedures (as defined by the French DRG classification) over 11 years (2002-2012). Hospitals with fewer than 300 surgical admissions per year were not included, because many of them closed during the study period. We considered separately public and private hospitals, as hospital funding was completely different between these two types before the introduction of case-based payment in all hospitals. The 46 private not-for-profit hospitals were classified in the public sector, as their hospital funding was the same as for public hospitals.

\section{Main outcome measure: readmission within $\mathbf{3 0}$ days following discharge}

For each selected surgery admission, the time from patient discharge to a new admission was calculated according to the linked information. Initial hospitalisations and stays ending in death or transfer, iterative treatments and neonatology were excluded. In 'iterative treatments', we considered 1 day admissions for treatments such as chemotherapy, radiation therapy and haemodialysis. All-cause readmission was defined as 'a new hospitalization within 30 days $^{30}$ following discharge after an admission for surgery, whatever the reason for this second admission' as done before, ${ }^{2526}$ that is, if a patient was readmitted for a reason other than the diagnosis for the first admission, it was still considered a readmission. The hospital where the readmission took place was also noted.

\section{Variables studied: characteristics related to readmission}

The characteristics of the admissions were studied according to the variables available in the national medical-administrative database, namely year of hospitalisation, age, gender, mode of admission (from home, via an emergency service and transfer), the type of hospital, morbidity (Charlson score, Major Diagnostic Categories of French classification in DRGs that we called DRG groups) and length of stay. ${ }^{15}$ We also added the urban/rural classification of patients' place of residence according to the French institute of statistics and censuses. We subdivided information regarding urban areas into three categories: city centres, suburbs of big cities and small towns.

\section{Statistical analysis}

In the first analysis, we studied the influence of the variables defined above (all dichotomised) on readmission at 30 days with two logistic regression models. The probability of readmission was analysed separately for the two types of hospital sector (ie, public and private). The first model (M0) concerned all hospital admissions for surgery.

The second model (M1) excluded DRG groups with low volumes of activity (burns, infectious diseases, HIV diseases, multiple trauma, psychiatry in acute care and other types of care). They also excluded cases with major modifications in care practices during the period, either for changes in care management (eg, in ophthalmology) or therapeutic changes for the treatment of HIV. Regarding ophthalmological surgery, since cataract surgery is more and more frequently performed to one eye and rapidly after to the other $(<1$ month after), we had to take into account this change with time, which 
results in an increase in readmission rates in ophthalmology substantially greater than in other specialties.

In the second analysis, an interrupted time series analysis was performed to measure changes in the readmission rate over time while taking into account the variables defined above. This model used monthly readmission rates over the study period and included a linear time trend. Three periods were considered: the pre-case-based payment system period (from 2002 to 2004), the implementation period (from 2005 to 2008) and the postimplementation period (from 2009 to 2012). In accordance with seasonal fluctuations, random error was modelled by an autoregressive model with a parameter at lag 12 .

We thus quantified the impact of the implementation as changes in the level and slope compared with the preimplementation period. SAS V.9.4 was used for all of the analyses. The threshold of statistical significance was set at $\mathrm{P}<0.05$.

\section{RESULTS}

\section{Descriptive study}

The study sample contained almost 52 million admissions, accounting for all admissions with DRGs related to surgery in hospitals with $>300$ admissions per year. Admissions with in-hospital deaths or without linkage information were excluded and represented $<5 \%$ of our admissions.

The number of admissions with surgery selected in the database increased from 4.1 million in 2002 to 5.3 million in 2012, for a total of 51.6 million admissions over the 11 years (table 1 ). Of the surgeries, $60 \%$ and $40 \%$ took place in profit-making private and in public or non-profit-making private hospitals, respectively. During the study period, there was a steady increase in the mean age of patients (from 48.6 to 51.3 years) and a decrease in the mean length of stay (from 4.3 to 3.0 days). The disease profile remained relatively stable, except for a slight increase in admissions in ophthalmology units.

Between 2002 and 2012, the readmission rate following admissions for surgery (figure 1) increased in both the public and private sectors: from $8.8 \%$ to $10.0 \%$ and $5.9 \%$ to $8.6 \%$, respectively. Although the overall readmission rate was higher in public than in private hospitals $(\mathrm{P}<0.001)$, its increase appeared to be relatively steady in both sectors. However, this increase was significantly greater in the private than in the public sector $(\mathrm{P}<0.001)$.

The descriptive results underlined the disparity in readmission rates at 30 days between the different DRG groups over the study period (figure 2), in terms of both volume and evolution. In 2012, the readmission rate ranged from $2.7 \%$ for ear, nose and throat surgery to $26 \%$ for haematology and $27 \%$ for the surgical treatment of burns. Two types of surgery in particular showed a major change in the readmission rate: ophthalmology and HIV-related surgery. For ophthalmology, the readmission rate increased from $9.3 \%$ in 2002 to $16.5 \%$ in 2012 in the public sector and from $10.0 \%$ to $19.7 \%$ in the private sector. For HIV-related surgery, the readmission rate in the public sector fell from $31.4 \%$ in 2002 to $25.4 \%$ in 2012 , but peaked at $39.3 \%$ in 2006 , with major variations from one year to another.

The profile for the evolution of readmission rates by type of surgery also differed according to the type of hospital and surgery (figure 2). For example, the increase in the readmission rate for ophthalmology was particularly pronounced in private hospitals, rising from $10.0 \%$ in 2002 to $19.7 \%$ in 2012. Concerning other types of surgery, the readmission rate for the public and private sectors remained quite stable.

\section{Multivariate models: study of factors associated with readmission}

After adjustment for the DRG groups and morbidity, the probability of readmission at 30 days increased with time (table 2, model M0) in both the public and private sectors. We can see that the effect of the risk of readmission also increased with age and that this effect was greater in the private than in the public sector (eg, for patients aged 80 years and over, $\mathrm{OR}=1.9$ in the public sector vs 5.3 in the private sector). Moreover, patients living in urban areas were slightly more at risk of readmission, with a more marked risk in small towns.

However, after excluding cases with major modifications in care practices during the period (such as ophthalmological surgery) or with low volumes of activity, the overall increase in the readmission rate found in model M0 was not retrieved for public hospitals and the readmission rate did not seem to increase with time after the implementation of the case-based payment (model M1).

\section{Interrupted time series model}

The series exhibited significant linear trends over the period (see figure 3). Rehospitalisation rates increased by 0.0170 percentage points per month in public hospitals $(\mathrm{P}<0.05)$ and by 0.0224 percentage points per month in private hospitals $(\mathrm{P}<0.001)$. However, the implementation of case-based payment was associated with a significant increase in rehospitalisation rates for private hospitals $(\mathrm{P}<0.001)$.

\section{DISCUSSION}

Our nationwide population-based analysis of 51.6 million hospital admissions for surgery over the 2002-2012 period found that the overall readmission rate within 30 days following discharge increased with time both in the public and private sectors, after adjustment for age, gender and comorbidities. The increase was greater in the private sector than in the public sector. However, after excluding cases with major modifications in care practices during the period, such as ophthalmological surgery, the overall increase in the readmission rate found in the previous regression logistic model was not retrieved and, for public hospitals, the readmission rate did not seem to have been influenced by the implementation of 


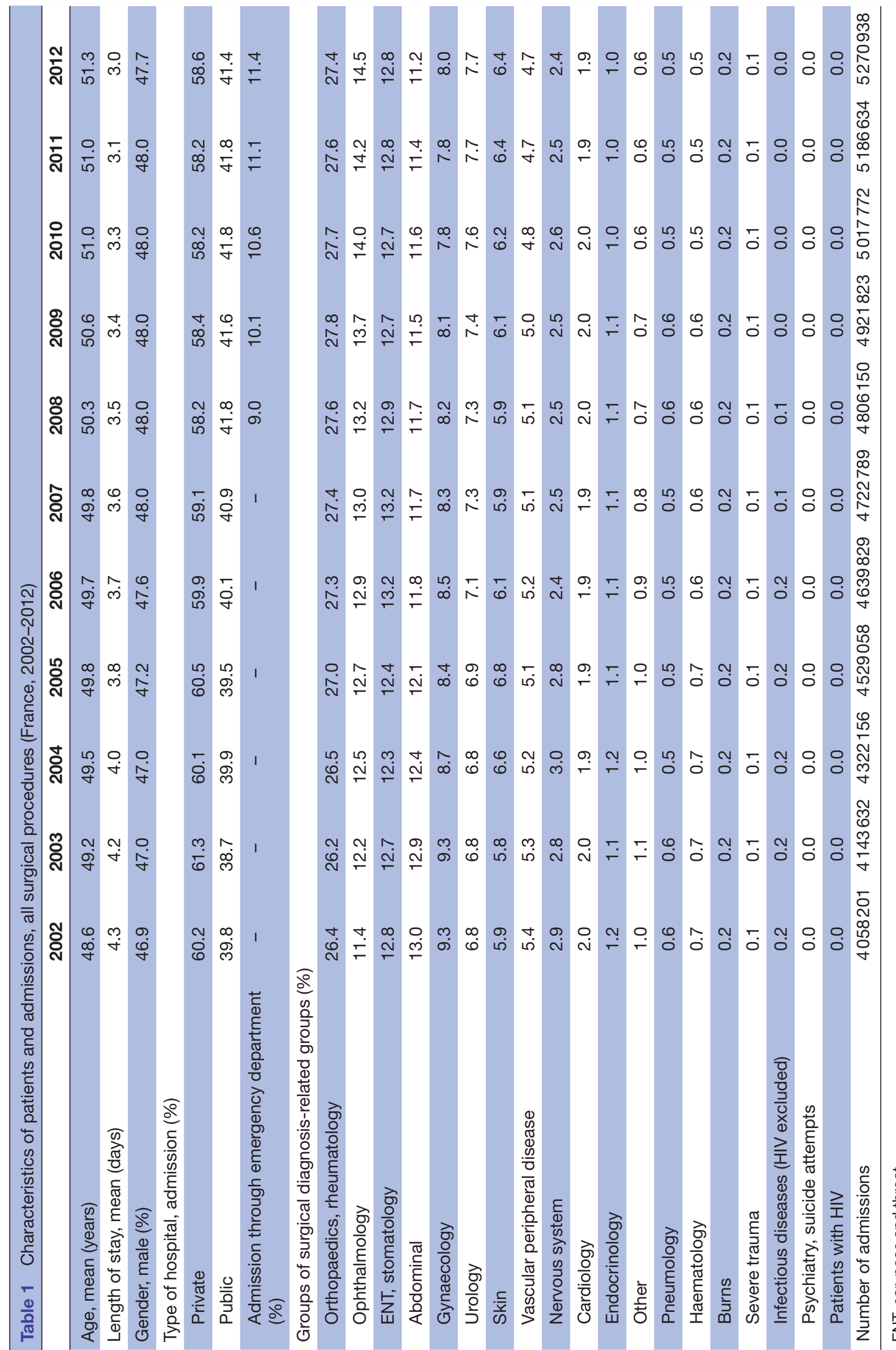




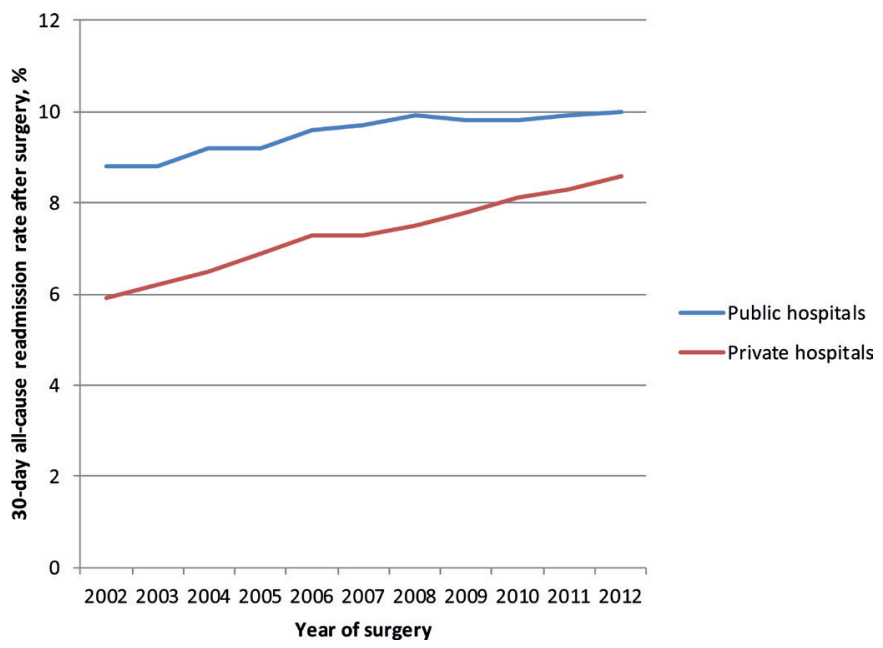

Figure 1 Thirty-day all-cause readmission rates after surgery according to hospital sector, all surgical procedures (France, 2002-2012).

case-based payment. The interrupted time series analysis confirmed that the implementation of case-based payment was only associated with a significant increase in rehospitalisation rates for private hospitals. These results suggest that hospital reimbursement is not the only determinant of readmission.

These findings contradict the results of a retrospective observational study in the USA, ${ }^{32}$ which found a decreased 30-day readmission rate following inpatient discharge for nine surgical specialties in the Veterans Health Administration (VHA) over a similar 10-year period (2001-2010). The fact that in France, no penalty is risked by hospitals in case of increased readmission rate may partially explain this difference. Moreover, our study included all types of surgery and specialties, including ophthalmology. We also considered all readmissions, whatever the sector, in contrast with the VHA study, in which patients having surgery at a VHA facility and then readmitted in the private sector could not be captured. In another study, comparing patients insured by Medicare before and after the implementation of the case-based payment system, ${ }^{33}$ the authors found that case-based payment was accompanied by a reduction in the length of stay. In parallel, the discharge mortality rate and the readmission rate did not increase. The same results were found by Kahn et $a l^{13}$ with a $24 \%$ decrease in the length of stay and an unchanged readmission rate. Another early study on the effects of implementing Medicare in the USA reported stable in-hospital mortality rates and care quality. ${ }^{34}$ At the same time, this stability of in-hospital mortality was put into perspective by Sager $e t$ al, who reported a significant rise in mortality at home and thus concluded that in-hospital deaths had been converted to at-home deaths in patients not covered by the new system. ${ }^{35}$ In Europe, it is difficult to say whether mortality rates have been affected by implementation of the case-based payment system. Studies have nonetheless shown that these systems are often accompanied by shorter lengths of stay and an increase in the number of admissions and in hospital productivity. ${ }^{562036}$ Cutler hypothesised that payment linked to activity could have influenced the readmission rate, given that these rates increased in hospitals with deficits and thus under financial pressure. ${ }^{14}$

The evolution of readmission rates was slightly different in the public and private sectors. In France, the former generally manages the most complex cases of each disease, including emergency cases. ${ }^{37}$ It is therefore not surprising to see a higher overall rate of readmissions in public than in private hospitals. However, comparison of the two sectors showed that the management of cataract surgery was reorganised faster in the private sector. The greater increase in readmissions in the private sector than in the public sector may be surprising, since the new pricing policy provided the least incentive for change in the private sector. The pricing policy before the case-based payment system already included payment according to activity in the private sector and readmissions were
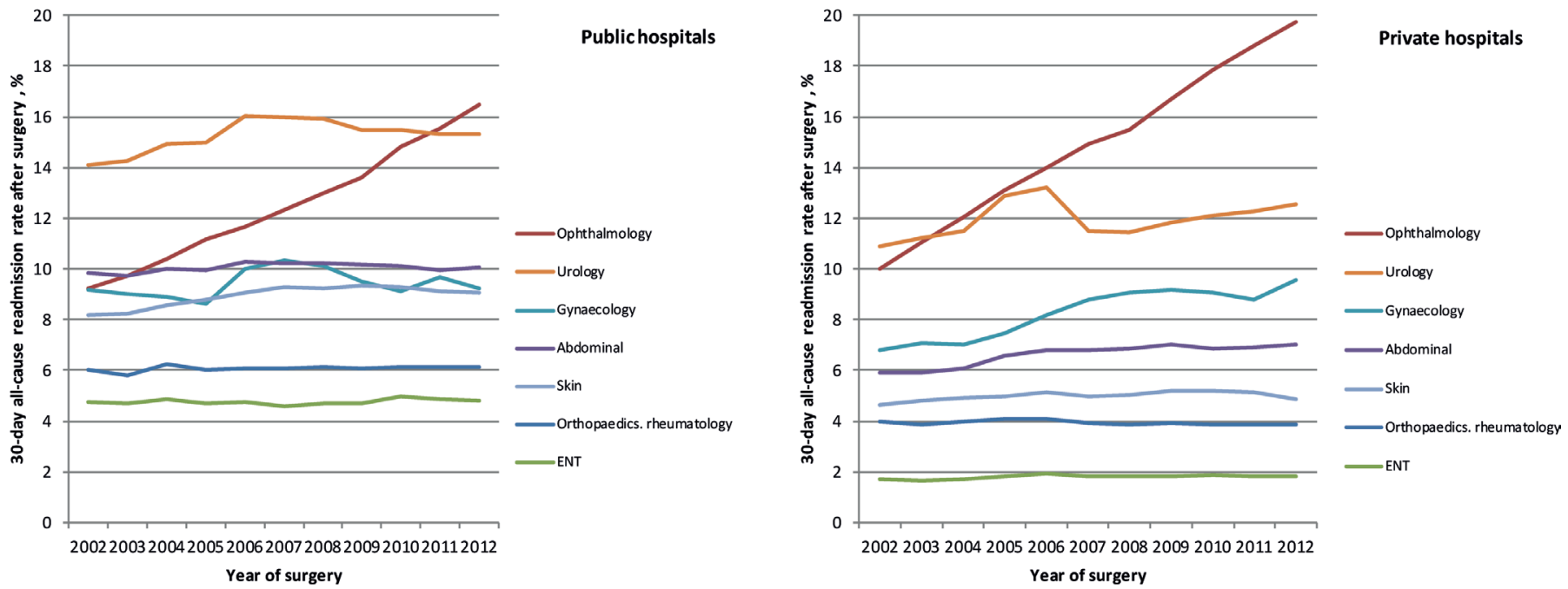

Figure 2 Thirty-day all-cause readmission rates after surgery according to the most frequent DRG groups, by hospital sector, all surgical procedures (France, 2002-2012). DRG, diagnosis-related group; ENT, ear, nose and throat. 
Table 2 Multiple logistic regression of 30-day all-cause readmission rates according to characteristics of patients and admissions, all surgical procedures (France, 2002-2012)

\begin{tabular}{|c|c|c|c|c|}
\hline & \multicolumn{2}{|c|}{ Public hospitals (ORs) } & \multicolumn{2}{|c|}{ Private hospitals (ORs) } \\
\hline & Model 0 & Model 1 & Model 0 & Model 1 \\
\hline \multicolumn{5}{|l|}{ Year of surgery } \\
\hline 2002 & Ref. & Ref. & Ref. & Ref. \\
\hline 2003 & 0.994 & $0.984^{* \star}$ & $1.023^{\star *}$ & 1.000 \\
\hline 2004 & $1.043^{\star \star}$ & $1.039^{\star \star}$ & $1.074^{\star \star}$ & $1.036^{\star \star}$ \\
\hline 2005 & $1.033^{\star \star}$ & $1.018^{\star \star}$ & $1.152^{\star \star}$ & $1.096^{\star *}$ \\
\hline 2006 & $1.084^{\star \star}$ & $1.070^{\star \star}$ & $1.212^{\star \star}$ & $1.147^{\star \star}$ \\
\hline 2007 & $1.093^{\star *}$ & $1.075^{\star *}$ & $1.223^{\star \star}$ & $1.121^{\star *}$ \\
\hline 2008 & $1.105^{\star \star}$ & $1.077^{\star \star}$ & $1.246^{\star \star}$ & $1.127^{\star \star}$ \\
\hline 2009 & $1.091^{* *}$ & $1.059^{* *}$ & $1.305^{\star *}$ & $1.151^{* *}$ \\
\hline 2010 & $1.090^{\star *}$ & $1.040^{\star *}$ & $1.351^{\star *}$ & $1.155^{\star \star}$ \\
\hline 2011 & $1.103^{\star *}$ & $1.045^{\star *}$ & $1.395^{\star \star}$ & $1.166^{\star *}$ \\
\hline 2012 & $1.103^{\star \star}$ & $1.033^{\star \star}$ & $1.448^{\star \star}$ & $1.191^{\star \star}$ \\
\hline \multicolumn{5}{|l|}{ Comorbidity } \\
\hline Charlson index (>0 vs $=0$ ) & $1.943^{\star *}$ & $2.061^{* *}$ & $1.529^{\star \star}$ & $1.812^{\star *}$ \\
\hline \multicolumn{5}{|l|}{ Admission } \\
\hline Home versus transfer from hospital & $0.899^{\star \star}$ & $0.850^{\star \star}$ & $0.640^{\star \star}$ & $0.613^{\star \star}$ \\
\hline \multicolumn{5}{|l|}{ Gender } \\
\hline Male versus female & $1.096^{\star \star}$ & $1.106^{\star \star}$ & $1.024^{\star \star}$ & $1.049^{\star \star}$ \\
\hline \multicolumn{5}{|l|}{ Age } \\
\hline$<10$ years & Ref. & Ref. & Ref. & Ref. \\
\hline $10-19$ years & $0.918^{*}$ & $1.010^{*}$ & $1.438^{\star *}$ & $1.404^{\star *}$ \\
\hline $20-29$ years & $1.112^{\star \star}$ & $1.274^{\star \star}$ & $2.636^{\star \star}$ & $2.592^{\star \star}$ \\
\hline $30-39$ years & $1.400^{\star *}$ & $1.624^{\star *}$ & $3.692^{\star *}$ & $3.650^{\star *}$ \\
\hline $40-49$ years & $1.398^{\star \star}$ & $1.599^{\star \star}$ & $3.544^{\star \star}$ & $3.401^{\star \star}$ \\
\hline $50-59$ years & $1.615^{\star *}$ & $1.850^{\star *}$ & $4.150^{\star *}$ & $3.869^{* \star}$ \\
\hline $60-69$ years & $1.712^{\star *}$ & $1.962^{\star *}$ & $4.567^{\star \star}$ & $4.142^{* \star}$ \\
\hline $70-79$ years & $1.777^{\star *}$ & $2.009^{* *}$ & $5.028^{* *}$ & $4.577^{\star *}$ \\
\hline 80 years and over & $1.954^{\star \star}$ & $2.263^{\star \star}$ & $5.304^{\star \star}$ & $5.433^{\star \star}$ \\
\hline \multicolumn{5}{|l|}{ Place of residence } \\
\hline City centre & $1.004^{\star}$ & 0.998 & $1.025^{\star \star}$ & $1.032^{* \star}$ \\
\hline Suburbs & $1.018^{\star *}$ & $1.008^{\star *}$ & $1.017^{\star \star}$ & $1.019^{\star \star}$ \\
\hline Small town & $1.021^{\star \star}$ & $1.011^{\star \star}$ & $1.025^{\star \star}$ & 1.002 \\
\hline Fixed effects for each DRG group & Included & Included & Included & Included \\
\hline Interaction term: DRG groupxyear & No & No & No & No \\
\hline Number of observations & 20893246 & 18036369 & 30459905 & 24736141 \\
\hline \multicolumn{5}{|l|}{ Concordance statistic } \\
\hline Concordant pairs (\%) & 66.7 & 66.2 & 71.4 & 69.9 \\
\hline
\end{tabular}

${ }^{* *} P<0.01$.

${ }^{*} P<0.10$.

†French classification of DRGs.

DRG, diagnosis-related group.

already paid for before implementation of the case-based payment system.

As this rise in readmissions did not seem to be only related to the pricing reform, one might wonder whether it was also related to changes in care practices. A more specific analysis of our results did not support this hypothesis. Two contrasting examples show the effect of changes in care practices on readmission rates. First consider the 


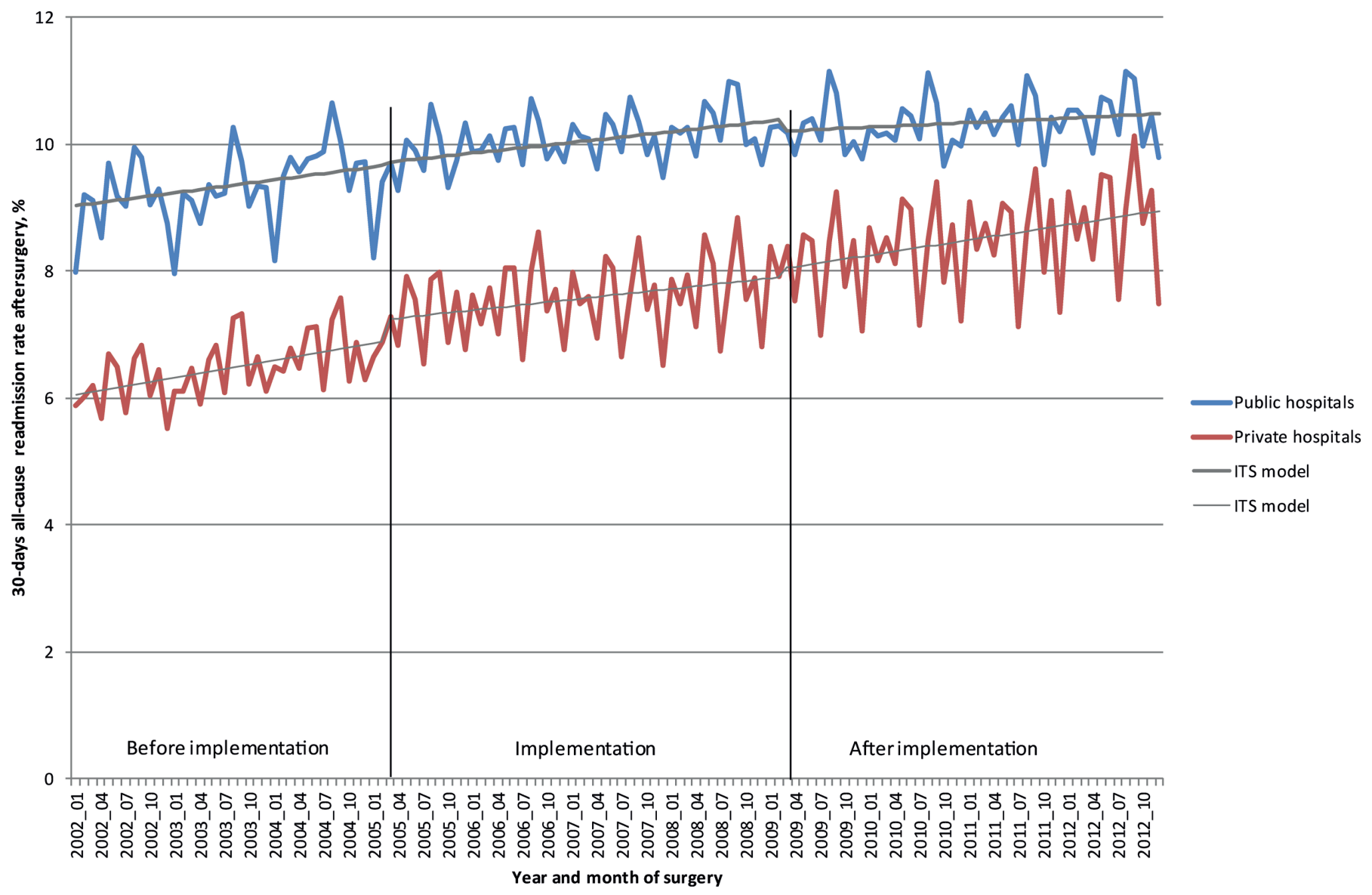

Figure 3 Global trends in 30-day all-cause readmission rates per month after surgery (France, 2002-2012): ITS analysis. ITS, interrupted time series.

case of cataract surgery, nearly 500000 surgeries per year in France. These procedures have moved from inpatient to outpatient hospitalisation with prompt recovery leading to a shortened delay between surgeries for each eye. Consequently, their increased readmission rates only reflect this shortened delay between surgeries for each eye due to the improvement in practices and not a secondary deleterious influence of hospital funding. Second, in HIV-related surgery, we observed changes in the opposite direction, with a decrease in the readmission rate, which may only reflect the improved efficacy of antiretroviral treatments leading to fewer recurrent hospitalisations. These observations suggest that to interpret these results, all changes (population, clinical practices and payment incentives) need to be considered for each group of diseases.

At the international level, the financial impact of readmissions to hospitals has led to the implementation of different policies aiming to limit such admissions as much as possible. The impact of these measures has been investigated in American studies showing that the decrease in the number of readmissions in the population studied did not stem from the implementation of such policies, but rather from the long-standing adaptation of practices of healthcare staff, as shown in our study. ${ }^{38}$ These results showed that an overall decrease in readmissions at 30 days has to be considered over the long term rather than as a direct and immediate result of healthcare policy. A secondary effect such as a concomitant increase in outpatient consultations needs to be considered as well. ${ }^{40}$ However, a recent study reported significant effects of such incentives, leading to decreases in readmission rates in small public-sector hospitals located in rural areas. ${ }^{39}$ In our study, we considered the place of residence of patients and not the location of the hospital as in France most hospitals are located in urban areas. We only found a slight effect of the patients' place of residence on readmissions. We do not think that this result can be affected by the risk of ecological fallacy as we only included one aggregated variable in our logistic regression model. ${ }^{41}$

In the USA, some hospitals regularly publish their 30-day readmission rates with regard to cardiovascular or pulmonary diseases. However, a recent analysis of factors associated with readmission conducted in a cohort of patients insured by Medicare showed that not all hospitals were equally affected by readmissions. ${ }^{42}$ After adjustment for the characteristics of individual patients, hospitals recording the highest readmission rates were those with patients who were the most likely to be readmitted to the hospital due to the complexity of their illness or a low socioeconomic status. ${ }^{43}$ In our study, we could not include the socioeconomic status of patients. We are 
aware that one plausible explanation for the increase in hospital readmissions could be related to the patient's socioeconomic environment, as social and economic support at home may not be sustained and place the patient at a higher risk of readmission. Indeed, the use of readmission as a marker of complications after an initial surgical admission remains controversial. Some studies reported that almost half of readmissions were not associated with a currently assessed complication. ${ }^{44}$ Moreover, readmissions after surgery may be associated with new postdischarge complications related to the procedure rather than exacerbation of complications related to a prior index hospitalisation ${ }^{45}$ or confounding issues such as substance abuse or homelessness. Some authors believe that reduced readmission rates alone cannot be used as an indicator of care quality; their effects must be studied more globally to determine whether such reductions coincide with improved quality of life in patients. ${ }^{46}$

To our knowledge, this study is the first to consider all hospital admissions resulting from all-cause readmissions within 30 days over such a long period in a given country. This study nevertheless has certain limitations. First, the global nature of readmission, chosen as an indicator in this study, can only be regarded as a partial assessment of the quality of surgical care. Other measurements should be considered, such as the mortality rate after hospitalisation. Among the readmissions identified, certain were scheduled and did not result from a complication following the first admission. It was not possible to distinguish between scheduled and unscheduled readmissions, because this information is not recorded in French claims data. This is why we decided to exclude admissions for ocular surgery in the M1 model so as to rule out most scheduled readmissions. Second, we could not compute a combined comorbidity score, as suggested by Mehta $e t$ $a l,{ }^{47}$ from the information available in discharge abstracts. Further research is needed, first to characterise readmissions, second to study the influence of the type or the location of hospitals in greater detail,${ }^{48}$ to consider readmissions after outpatient surgery, and finally to better explain the relationship between readmissions and length of hospital stay. ${ }^{49}$

\section{CONCLUSION}

Our nationwide observational study is the first to consider all hospital admissions resulting from all-cause readmissions within 30 days after surgery over such a long period. It suggests that despite the slight temporary rise in readmissions during the implementation of the case-based payment system, this pricing reform does not appear to have had a significant long-lasting effect on readmissions at 30 days in the public sector. The increase in the readmission rate at 30 days after an admission for surgery appears to be related mainly to modifications in care practices, notably for cataract surgery and, second, to a structural modification associated with the ageing patient population. To interpret these results, further studies are needed to examine the influence of the different changes in populations and clinical practices on readmissions for each group of diseases.

\section{AVAILABILITY OF DATA AND MATERIALS}

The PMSI database was transmitted by the national agency for the management of hospitalisation data (ATIH number 2015-111111-47-33). The use of these data by our department was approved by the National Committee for Data Protection. We are not allowed to transmit these data.

\section{Author affiliations}

${ }^{1}$ Department of Biostatistics and Bioinformatics (DIM), University Hospital, Dijon, France

${ }^{2}$ Division of Research and Statistics, Ministry of Health, Paris, France

${ }^{3}$ School of Economics, University of Sorbonne, Paris, France

${ }^{4}$ The Robert F. Wagner School of Public Service, New York University, New York, USA

${ }^{5}$ Laboratoire d'Economie de Dijon, Université Bourgogne/Franche-Comté, Inserm U1200, CNRS UMR 6307, Dijon, France

${ }^{6}$ Department of Thoracic Surgery, University Hospital, Dijon, France

${ }^{7}$ Department of Ophthalmology, University Hospital, Dijon, France

${ }^{8}$ Eye and Nutrition Research Group, Bourgogne Franche-Comté University, Dijon,

France

${ }^{9}$ Clinical Investigation Center, Dijon University Hospital, Dijon, France

${ }^{10}$ Biostatistics, Biomathematics, Pharmacoepidemiology and Infectious Diseases (B2PHI), INSERM, UVSQ, Institut Pasteur, Université Paris-Saclay, Paris, France

Contributors AV and EY conceptualised and designed the study, interpreted the data and wrote the paper. AR contributed substantially to writing the manuscript. VR, MG, $A B$ and $C C-G$ participated in the interpretation of the results and reviewed and revised the manuscript drafts. $C Q$ oversaw the data analysis and interpretation and contributed substantially to writing the manuscript. All authors accept responsibility for the paper as published.

Funding This research did not receive any specific grant from funding agencies in the public, commercial or not-for-profit sectors.

Competing interests None declared.

Patient consent Not required.

Ethics approval This study was approved by the National Committee for Data Protection (registration numbers: (a) 1576793; (b) 913291 for Dijon University Hospital and (c) 723116 for the Ministry of Health) and therefore was conducted in accordance with the Declaration of Helsinki. Written consent was not needed for this study.

Provenance and peer review Not commissioned; externally peer reviewed.

Data sharing statement No additional data are available.

Open Access This is an Open Access article distributed in accordance with the Creative Commons Attribution Non Commercial (CC BY-NC 4.0) license, which permits others to distribute, remix, adapt, build upon this work non-commercially, and license their derivative works on different terms, provided the original work is properly cited and the use is non-commercial. See: http://creativecommons.org/ licenses/by-nc/4.0/

(c) Article author(s) (or their employer(s) unless otherwise stated in the text of the article) 2018. All rights reserved. No commercial use is permitted unless otherwise expressly granted.

\section{REFERENCES}

1. Fetter RB, Freeman JL. Diagnosis related groups: product line management within hospitals. Acad Manage Rev 1986;11:41-54.

2. Fetter RB. Diagnosis Related Groups: Understanding Hospital Performance. Interfaces 1991;21:6-26.

3. McMahon LF, Fetter RB, Freeman JL, et al. and DRG-based prospective payment. Hosp Health Serv Adm 1986;31:62-74.

4. Roger France FH, Roger FH. Case mix use in 25 countries: a migration success but international comparisons failure. Int $\mathrm{J}$ Med Inform 2003;70(2-3):215-9. 
5. Dismuke CE, Sena V. Has DRG payment influenced the technical efficiency and productivity of diagnostic technologies in Portuguese public hospitals? An empirical analysis using parametric and nonparametric methods. Health Care Manag Sci 1999;2:107-16.

6. Dismuke CE, Guimaraes P. Has the caveat of case-mix based payment influenced the quality of inpatient hospital care in Portugal? Appl Econ 2002;34:1301-7.

7. Or Z. Implementation of DRG Payment in France: issues and recent developments. Health Policy 2014;117:146-50.

8. Noord P, Hagen T, Iversen T. The Norwegian Health Care System [Internet]. OECD Economics Department Working Papers 1998;198:32.

9. Pirson M, Van den Bulcke J, Di Pierdomenico L, et al. Medical and economic evaluation of oncological inpatients in 14 Belgian hospitals]. Bull Cancer (Paris). nov 2015;102:923-31.

10. Lilford RJ, Brown CA, Nicholl J. Use of process measures to monitor the quality of clinical practice. BMJ 2007;335:648-50.

11. Thomas JW, Guire KE, Horvat GG. Is patient length of stay related to quality of care? Hosp Health Serv Adm 1997;42:489-507.

12. Martin S, Street A, Han L, et al. Have hospital readmissions increased in the face of reductions in length of stay? Evidence from England. Health Policy 2016;120:89-99.

13. Kahn KL, Keeler EB, Sherwood MJ, et al. Comparing outcomes of care before and after implementation of the DRG-based prospective payment system. JAMA 1990;264:1984-8.

14. Cutler DM. The Incidence of Adverse Medical Outcomes Under Prospective Payments [Internet: National Bureau of Economic Research, 1993. Report No.: 4300. http://www.nber.org/papers/ w4300 (accessed 1 Feb 2017).

15. Bahrami S, Holstein J, Chatellier G, et al. Using administrative data to assess the impact of length of stay on readmissions: study of two procedures in surgery and obstetrics]. Rev Epidemiol Sante Publique. apr 2008;56:79-85.

16. Moghavem N, McDonald K, Ratliff JK, et al. Performance Measures in Neurosurgical Patient Care: Differing Applications of Patient Safety Indicators. Med Care 2016;54:359-64.

17. Rosen AK, Chen Q, Shwartz M, et al. Does Use of a Hospital-wide Readmission Measure Versus Condition-specific Readmission Measures Make a Difference for Hospital Profiling and Payment Penalties? Med Care 2016;54:155-61.

18. Serdén L, Lindqvist R, Rosén M. Have DRG-based prospective payment systems influenced the number of secondary diagnoses in health care administrative data? Health Policy 2003;65:101-7.

19. Böcking W, Ahrens $U$, Kirch W, et al. First results of the introduction of DRGs in Germany and overview of experience from other DRG countries. J Public Health 2005;13:128-37.

20. Herwartz H, Strumann C. On the effect of prospective payment on local hospital competition in Germany. Health Care Manag Sci 2012;15:48-62.

21. Guccio C, Lisi D, Pignataro G. Readmission and Hospital Quality under Prospective Payment System [Internet]. 2014. https://mpra.ub. uni-muenchen.de/56490/

22. Abdul-Aziz AA, Hayward RA, Aaronson KD, et al. Association Between Medicare Hospital Readmission Penalties and 30-Day Combined Excess Readmission and Mortality. JAMA Cardiol 2017;2:200-3.

23. Desai NR, Ross JS, Kwon JY, et al. Association Between Hospital Penalty Status Under the Hospital Readmission Reduction Program and Readmission Rates for Target and Nontarget Conditions. JAMA 2016;316:2647-56

24. Danino JF, Taylor T, Metcalfe CW, et al. Readmission rates and financial penalties after ear, nose and throat surgery: how can we improve? Br J Hosp Med 2015;76:655-7.

25. Gusmano M, Rodwin V, Weisz D, et al. Comparison of rehospitalization rates in France and the United States. $J$ Health Serv Res Policy 2015;20:18-25.

26. Lainay C, Benzenine E, Durier J, et al. Hospitalization within the first year after stroke: the Dijon stroke registry. Stroke 2015;46:190-6.

27. Delmas MC, Marguet C, Raherison C, et al. Readmissions for asthma in France in 2002-2005. Rev Mal Respir 2011;28:e115-e122.
28. Abdulmalak C, Cottenet J, Beltramo G, et al. Haemoptysis in adults: a 5-year study using the French nationwide hospital administrative database. Eur Respir J 2015;46:503-11.

29. Creuzot-Garcher C, Benzenine E, Mariet AS, et al. Incidence of Acute Postoperative Endophthalmitis after Cataract Surgery: A Nationwide Study in France from 2005 to 2014. Ophthalmology 2016;123:1414-20.

30. Lorgis L, Cottenet J, Molins G, et al. Outcomes after acute myocardial infarction in HIV-infected patients: analysis of data from a French nationwide hospital medical information database. Circulation 2013;127:1767-74.

31. Pagès $\mathrm{PB}$, Cottenet $\mathrm{J}$, Mariet $\mathrm{AS}$, et al. In-hospital mortality following lung cancer resection: nationwide administrative database. Eur Respir J 2016;47:1809-17.

32. Han S, Smith TS, Gunnar W. Descriptive analysis of 30-day readmission after inpatient surgery discharge in the Veterans Health Administration. JAMA Surg 2014;149:1162-8.

33. Davis C, Rhodes DJ. The impact of DRGs on the cost and quality of health care in the United States. Health Policy 1988;9:117-31.

34. DesHarnais S, Kobrinski E, Chesney J, et al. The early effects of the prospective payment system on inpatient utilization and the quality of care. Inquiry 1987;24:7-16.

35. Sager MA, Easterling DV, Kindig DA, et al. Changes in the location of death after passage of Medicare's prospective payment system. A national study. N Engl J Med 1989;320:433-9.

36. O'Reilly J, Busse R, Häkkinen U, et al. Paying for hospital care: the experience with implementing activity-based funding in five European countries. Health Econ Policy Law 2012;7:73-101.

37. Reuter PG, Kernéis S, Turbelin C, et al. [Orientation of patients referred by their general practionner to the public or private hospital sector in France: A prospective epidemiologic study]. Rev Med Interne 2012;33:672-7.

38. DeVore AD, Hammill BG, Hardy NC, et al. Has Public Reporting of Hospital Readmission Rates Affected Patient Outcomes?: Analysis of Medicare Claims Data. J Am Coll Cardiol 2016;67:963-72.

39. McGarry BE, Blankley AA, Li Y. The Impact of the Medicare Hospital Readmission Reduction Program in New York State. Med Care 2016:54:162-71.

40. Hofstede SN, van Bodegom-Vos L, Kringos DS, et al. Mortality, readmission and length of stay have different relationships using hospital-level versus patient-level data: an example of the ecological fallacy affecting hospital performance indicators. $B M J$ Qual Saf 2017:doi: 10.1136/bmjqs-2017-006776. [Epub ahead of print].

41. Lu N, Huang KC, Johnson JA. Reducing excess readmissions: promising effect of hospital readmissions reduction program in US hospitals. Int J Qual Health Care 2016;28:53-8.

42. Barnett ML, Hsu J, McWilliams JM. Patient characteristics and differences in hospital readmission rates. JAMA Intern Med 2015;175:1803-12.

43. Leape LL. Hospital readmissions following surgery: turning complications into "treasures". JAMA 2015;313:467-8.

44. Morris MS, Deierhoi RJ, Richman JS, et al. The relationship between timing of surgical complications and hospital readmission. JAMA Surg 2014;149:348-54.

45. McIntyre LK, Arbabi S, Robinson EF, et al. Analysis of risk factors for patient readmission 30 days following discharge from general surgery. JAMA Surg 2016;151:855-61.

46. Burgess JF, Hockenberry JM. Can all cause readmission policy improve quality or lower expenditures? A historical perspective on current initiatives. Health Econ Policy Law 2014;9:193-213.

47. Mehta HB, Dimou F, Adhikari D, et al. Comparison of comorbidity scores in predicting surgical outcomes. Med Care 2016;54:180-7.

48. Metcalfe D, Olufajo OA, Zogg CK, et al. Are older adults with hip fractures disadvantaged in level 1 trauma centers? Med Care 2016;54:616-22.

49. Sedrakyan A, Kamel H, Mao J, et al. Hospital readmission and length of stay over time in patients undergoing major cardiovascular and orthopedic surgery: a tale of 2 states. Med Care 2016;54:592-9. 